\title{
Animation and Socialization Process: Gender Role Portrayal on Cartoon Network
}

\author{
Shumaila Ahmed ${ }^{1,2} \&$ Juliana Abdul Wahab ${ }^{1}$ \\ ${ }^{1}$ School of Communication, Universiti Sains Malaysia, Malaysia \\ 2 Dept. of Media Studies, The Islamia University of Bahawalpur, Pakistan \\ Correspondence: Shumaila Ahmed, School of Communication, Universiti Sains Malaysia, Penang, Malaysia. Tel: \\ 60-17-350-5968. E-mail: shumailaanoosh2006@yahoo.com
}

\author{
Received: September 18, 2013 Accepted: December 19, $2013 \quad$ Online Published: January 27, 2014 \\ doi:10.5539/ass.v10n3p44 \\ URL: http://dx.doi.org/10.5539/ass.v10n3p44
}

\begin{abstract}
Animated cartoons for young children have always been significant in the life of many children all over the world. The present research is conducted to investigate the gender representation of male and female characters in the animated cartoons broadcasted from Cartoon Network, the worldwide popular channel for children. This popular TV genre is broadcasted in different languages from Japan, Pakistan, Australia, Taiwan, Korea, Malaysia, India and many other countries of Asia and pacific as well. Content analysis of selected animated genre or cartoons broadcasted from the month of Jan to July, 2013 is done. The objective of this paper is to examine the representation of male and female characters in children's animated genre. The universe for the present article is the most popular cartoon channel for children. The technique of purposive sampling is used to analyze the data and to represent the findings of the research. The relationship among the data collected is also explored. The findings of the study reveal that the worldwide popular animated cartoon channel for children portrays the male and female characters in a biased and stereotypical way, which to a certain extent play an important role in socialization process for shaping and constructing ideas about male and female's position and characteristics in society.
\end{abstract}

Keywords: gender, animation, Cartoon Network, stereotyping, socialization

\section{Introduction}

Media and especially the television can play a very important and vital role in the process of learning of young children from a very early age (William, 1981). Television medium is considered and have always been identified as the most powerful and greatly active in shaping and molding the behavior of children towards the gender roles in the society. Whatever the animated materials the children watch on television, became a part of their socialization process later. Apart from the media, socialization process in actual fact involves a number of elements such as family, peer group and society. However, this article argues that media has always have played a significant role in the modern society in disseminating information, ideas and values about society. In this particular context, television arguably one of the important medium that plays its part through entertainment in a very fast pace. Due to a flexible nature, children learn very easily through entertainment and whatever they watch on television in their early age. Often times they try to adopt and socialize themselves according to the culturally accepted and established gender roles. According to Downs and Harrison, (1985) the process of socialization starts through the regular viewing of television programs from very early age in childhood that could be responsible in shaping and molding their interpretations and perceptions towards the social values regarding gender. Therefore with these kinds of values being cultivated to them, it is very important to investigate the representation of female to male characters in the animated television genre.

The behavior, skills, social and cultural values which the people or children learn or adopt through their culture and social norms is called socialization. Media plays a very vital role in the socialization of a child or adult, through different storyline, characters and dramatization of different genders through different themes and portrayals. Gender has been portraying stereotypically for a long period in the history of media. It was proved through a number of studies that the way the genders are stereotypically portrayed in a number of animated genre play a significant role in the socialization process of children in their childhood and adult age (Signorielli, 1990). Although media seem to be as a prominent agent in socializing children's thoughts and behaviors, Grusec 
and Hastings, (2007) point that the gendered behaviors of men and women are established and created through the environment and social groups like parents, teachers, and peer group which they learn from the society, consciously or unconsciously. Whilst other agents are recognized to play equally important role in the aspect of socialization this article argues that the importance of media is still there with the other agents as well. Moreover, a number of studies done by different scholars like Silverstein, Peterson and Kelly (1986) revealed that all those characters and themes which are portrayed in media, usually become a part of social practices in real life. Therefore the way the male and female characters are represented in the media, usually mould the way of thinking of children and affect accordingly their process of socialization and behaviors towards society. It is also believed such representation of gender is connected to the concept of patriarchy and commercialization factors that administer television industry in general.

\section{Literature Review}

For decades, the animated genre has been very popular and commercially successful all over the world. These animated programs started from the silent films and then were changed into full length motion pictures or animated films. Animation is the graphic representation of drawn pictures to show movement. A series of drawings are linked together and usually photographed by a camera. In early 1900 when Animation was started, it was an extremely labor intensive to link or join together the hundreds of drawings or pictures per minute of a film. Walt Disney introduced new innovation to animation and in 1937; the first full length animated cartoon film was produced. In 1995 "Toy story" was the first animated cartoon film which was animated on Computer.

On Oct 01, 1992, Turner Broadcasting system launched an Animated Cartoon Channel as a cable and Satellite television channel in America. Jim Samples was the founder of this channel. Cartoon Network was launched when there was already a popular Animated Cartoon channel, Nickelodeon which was very popular among the young audience. Therefore from its beginning, the Cartoon Network has to face a big challenge and competition.

Presently, there are a number of world famous television children channels and animated film companies, which are contributing a lot in the production of good and highly commercialized films, like Disney films, Warner brothers films, Fox films and Dream Works films. Although these animated films have been becoming more entertaining and attractive, on the other hand, some of the issues are still there; which are mainly concerned about the portrayal or stereotypical representation of male and female characters in these animated cartoons. According to Thompson, \& Zerbinos (1995) as children start spending a great part of their time on watching television and animated cartoons at very early age, gender representation in children's programs deserves much importance and attention. As it has already argued, television content plays a major role in conveying the certain messages to the young audience. Gender is a term which refers to the behavior of a sex in a particular culture or society (Aries, 1996). Being a male or female member of the society, define the gender of a person. It is actually the masculine or feminine behavior or characteristics of a men or women which he or she shows towards the society that identifies their role and position towards the cultural norms and gender relationships.

England, (2011) examines the Disney princess movies and found that gender representation in cartoons is just the same as it was many years ago. The traditional image of male and female characters is just the same. Male characters are always dominating and rescue the female characters and female cartoon character is always portrayed as smart, beautiful and sexy. Likewise Jeanne \& Debra (1996) argued that in most of the animated films, the male characters are usually projected as aggressive, full of action and violent whilst female characters are proved to be passive and useless as well as sub-ordinate to man. During the last few years a number of studies have proved that in majority of animated cartoons, not only the females are portrayed stereotypically but also the male characters as well are projected in a stereotypical manner in media all over the world. Moreover, Thompson, \& Zerbinos, (1995) studied the animated cartoons in American television and found that the animated cartoon which were shown before 1980 on television had represented the male and female characters more stereotypically than which were produced after 1980. The male characters were more aggressive and stronger while female characters were more beautiful, smart with ideal prettiness in feminine characters. Moreover the male characters were outnumbered 2 ratios 1 to female characters in most of the animated cartoon films. Furthermore, male characters in animated cartoons, not only outnumbered the female characters but are portrayed in a variety of different roles and especially in characters of good occupations (Levinson, 1975). On the other hand the female are just represented in a few typical type of roles and characters of being a sex symbol or an assistant and house lady with very few characters of occupations like teacher, nurse, girlfriend or mother. Till 1980 the gender portrayal has been the similar in more or less all of the kids' films and cartoons.

After 1980 the situation of gender portrayal started to change, male characters started to look more intelligent in dealing but more aggressive in actions as well. Rather than the female characters being portrayed in a feminine 
manner, the animated cartoon also started to project and portrayed female characters in action role. However, it is observed that at the same time they are still portrayed as stupid in comedy roles as and less intelligent than their male counterparts in most of the animated cartoon films (Thompson \& Zerbinos, 1995). The actual reason of all such kind of representation is very much in line with patriarchal ideology that promotes male domination in society. Likewise in the recent years, Weirsma (2000) argued that male characters have always been outnumbered the female characters in the Disney films for many years. Females are shown best at home characters and always under-represented while males are always shown as powerful and over-represented characters.

Wiserma, (2011) has found that from many years of history the gender role portrayal has not progressed according to the equality of male and female in the social development in the society because media is not portraying the real images and balanced perspective about men and women. There is still an unbalanced representation of female to male characters in the animated cartoons of children.

On the other hand a study done by Dietz, T. L (1998) found that female characters are shown just as a sex object for play for men because most of the video games which are made for men are targeted on playing with women as a sex object. Likewise Dill \& Thill, (2007) analyzed video games and found that $83 \%$ male characters are shown aggressive and strong while $60 \%$ female were portrayed as sexual object. In most of the games they were exploited sexually and victimized by the male character. England, (2011) insists after a critical analysis of most popular animated films, usually the characters in children's films are portrayed according to their masculine and feminine characteristics and trends. Most of the animated cartoons are found to be stereotyped in the portrayal of male and female characters. Male characters are portrayed to be more powerful and female characters are proved to be more attractive sexually.

With the passage of time the male characters are started to be represented in a variety of roles and it is also revealed that there is an obvious improvement in the characterization of male characters but in case of female characters there is a very little improvement. It is also observed that in action as well as comedy cartoons and films the domination of male characters is very obvious and clear. The unbalanced and stereotypical representation of gender roles in animated cartoons, arguably play an important part in modeling gendered behavior in children. Therefore it is important to examine the recent content of animated cartoon with regards to gender representation to understand the images, values and perspectives and ideas instilled for children.

\section{Conceptual Framework}

Television content is loaded with ideological perspectives that help shape and disseminate information and ideas about society through cultural and political perspectives. Media and especially television promotes the dominant ideology such as patriarchal values which maintain the existing social order. Patriarchal ideology proves to be the main cause of discrimination against women. As hegemony is the power and domination of one social group over the other therefore through the control of institution and the media, cultural and political hegemony is formed by the consensus through the media organizations. Media is the one which actually promotes the domination of state and identifies the domination of male over female. Especially in case of gender role portrayal in the media, hegemony and patriarchy have been derived as the sole reason of gender stereotyping.

Animated cartoons have become part and parcel of children's growing up activities. Therefore gendered portrayals in animated cartoons could communicate ideas and give values on how children should view and understand gendered behavior in society. It is already argued that media is not the sole agent in the socialization process, however it is recognized that the media play a significant role in children's socialization process. Through the social learning theory, it is commonly believed that children's beliefs, social behaviors and general ideas about gender and gender roles in society are usually molded and shaped by the gender role portrayals in the animated cartoons (Martin et al. 2002). Social learning theory suggests that children start learning smoothly and steadily from the program they watch on media and especially on television. From very early age of their life, they start learning the behaviors which are according to their sex or gender in their social world. Observational learning could be one of the strongest factors in the effectiveness of social learning theory. In the presence of other active agents, television is considered crucial in contributing and shaping human behaviors, especially young children, who learn regularly on daily basis through the animated cartoons shown on television's animated cartoon channels like Cartoon Network.

Social learning theorists believe that positive and effective behavioral change could be brought in the gender roles of children at very early age through the media programs or animated cartoons. As an important agent of social identity like the other agents such as friends, parents and social groups, the animated cartoons and television could also mould the minds of children towards their real identification in society (Holtzman, 1984). 
Therefore this article argues that the more the children are exposed to stereotypical materials, the more chances they will learn and adopt the social practices about the gender behaviors from the animated cartoons on television, which they use to watch during most of the time of the day. Therefore in the presence of hegemonic control of state's patriarchal ideology and through stereotypical portrayal, the young boys are trained to learn to be more active, intelligent and aggressive while the young girls were encouraged to become attractive as well as passive. Therefore due to the existing values about gender which is disseminated through animated cartoons it is quite possible that in the process of socialization, all these kind of stereotypical representation of gender could be resulted in inferiority and superiority complex in girls and boys respectively.

\section{Data Analysis and Findings}

The main aim of this study is to examine the gender portrayal of male and female characters in animated cartoons through the method of content analysis of animated films or cartoons broadcasted through Cartoon Network, a worldwide popular television channel for children. Cartoon Network is a renowned television channel which is broadcasted from more than thirty countries all over the world from Asia, Latin America, Europe, Africa and Middle East. From all these countries, this animated cartoon television channel is broadcasted in their local languages such as English, Sapanish, French, Hindi, Arabic and Urdu etc. Therefore with the understandable local languages the reason of popularity of the selected Animated channel of television, Cartoon Network has augmented and its role as one of agent in the Socialization of young children has also been increased. The young as well as audience of all other ages from all over the world, just love to watch this channel regularly.

The methodology involved in the analysis can be divided in two parts. The first part concerns with the quantitative aspect which has examined the numerical representation of male and female characters in the children's animated cartoons and about the characters represented on that particular channel, during the period of January-June, 2013. The method of purposive sampling is selected. Most popular and regular series of animated cartoons broadcasted from the channel of Cartoon Network are selected. All the Mondays in a month are selected and coded for sampling. As these cartoon serials are repeated during the whole week therefore consecutive day and night for every Monday are selected and coded. Total 24 days or nights are taken in which the total episodes of broadcasted cartoons were also 24 , because all the selected cartoons are shown everyday with repeat broadcasts during the 24 hours of the day.

Furthermore a content analysis has been done to examine the gender construction of each main character, their social role in those animated cartoons and lastly the way they are represented by the means of appearance. This study investigates how children's animated cartoons play a key role in shaping the gender behaviors. Themes and characters are coded according to the male and female traits. Traits were examined in respect of behaviors, appearance, intelligence and interactions. In the presence of most common traits of male and female characters in animated cartoons, the appearance indicators were designed and decided and analyzed. The findings are revealed about the masculine and feminine representation of male and female characters in the animated cartoon on Cartoon Network. 
Table 1. Female/Male character-oriented theme in popular animated cartoons on Cartoon Network Channel from $1^{\text {st }}$ January $2013-31^{\text {st }}$ June 2013

\begin{tabular}{llccc}
\hline \multirow{2}{*}{ Animated film/cartoon } & Character-oriented theme & \multicolumn{2}{c}{ Main Characters } & Total Characters \\
& & Male & Female & \\
\hline Ben 10 & Male & 03 & 02 & 05 \\
Scooby Doo & Male & 03 & 02 & 05 \\
Tom \& Jerry show & Male & 04 & 01 & 05 \\
Power puff girls & Female & 03 & 05 & 08 \\
Thunder Cats & Male & 13 & 02 & 15 \\
Bakugan & Male & 06 & 08 & 14 \\
Dragon Balls Z & Male & 07 & 02 & 09 \\
Pokémon & Male & 09 & 03 & 12 \\
Generator ReX & Male & 07 & 02 & 09 \\
Batman & Male & 03 & 01 & 04 \\
Total & Male:09 & 58 & 28 & 86 \\
& Female:01 & & & \\
\hline
\end{tabular}

Table 1. Shows that there are ten most popular and regular animated cartoons broadcasted from Cartoon Network from January 01 to June 31, 2013. Among all the selected animated cartoons, only 01 out of 10 total cartoons are female character-oriented while 09 are male-character-oriented. In female-oriented cartoons the main character is female and the main theme revolves around the achievements of female while in male-oriented films the main character is always a male and theme of that cartoon is always revolve around the action and achievements of men. So it is revealed that $90 \%$ animated cartoons are male-oriented and only $10 \%$ animated cartoons are female-oriented. Similarly the Table 1 proves that total 86 characters were shown in the selected animated cartoons in which 58 were male characters while 28 were female characters.

Table 2. Ratio of female to male characters in popular animated cartoons on Cartoon Network from $1^{\text {st }}$ January $2013-31^{\text {st }}$ June 2013

\begin{tabular}{ccc}
\hline Total characters $\underline{\mathrm{n}}$ & Male characters $\%$ & Female characters $\%$ \\
\hline 86 & $67.4 \%$ & $32.6 \%$ \\
\hline
\end{tabular}

Table 2 shows the ratio of female to male characters which proves that $67.4 \%$ characters were male and only $32.6 \%$ characters were female. These results revealed that male characters out-numbered female characters in the animated cartoons broadcasted from the worldwide popular channel, Cartoon Network.

Table 3. Ratio appearance indicators of female to male characters in popular animated cartoons on Cartoon Network from $1^{\text {st }}$ January $2013-31^{\text {st }}$ June 2013

\begin{tabular}{lcc}
\hline Appearance Indicators & Male characters \% & Female characters \% \\
\hline Strong and Brave & $70.4 \%$ & $29.6 \%$ \\
Sexual and Attractive & $10.0 \%$ & $90.0 \%$ \\
\hline
\end{tabular}

Table 3. Shows the ratio appearance Indicators of Female to Male Characters in the animated cartoons broadcasted from Cartoon Network during the selected period. It is revealed through the analysis of appearance indicators in the animated cartoons that $70.4 \%$ male characters were portrayed as strong and powerful in most of the animated films while only $29.6 \%$ females were shown in powerful and strong characters. While the female characters are portrayed as passive and weak in most of the animated films and cartoons. The findings revealed that $90.0 \%$ female characters are portrayed as sexually attractive, physically smart and beautiful while at the 
same time only $10 \%$ male characters were represented as sexually attractive and smart.

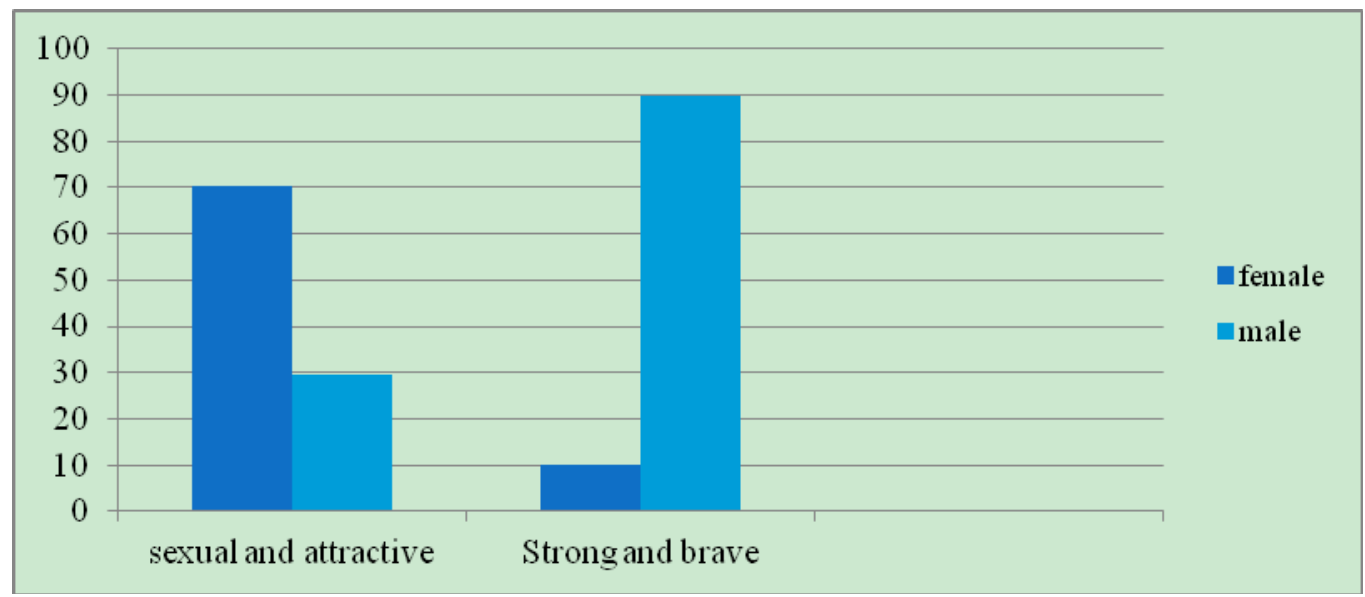

Figure 1. Ratio appearance indicators of female to male characters in the popular animated cartoons on Cartoon Network from $1^{\text {st }}$ January $2013-31^{\text {st }}$ June 2013

Figure 1 shows that $70.4 \%$ male characters were portrayed as strong and powerful in most of the animated cartoons while only $29.6 \%$ females were shown in powerful and strong characters. This means that male characters have outnumbered female characters in the matter of power and intelligence.

On the other hand, female characters have outnumbered male characters, when the appearance indicator of attractiveness is analyzed. The findings revealed that $90.0 \%$ female characters are portrayed as sexually attractive, physically smart and beautiful while at the same time only $10 \%$ male characters were represented as sexually attractive and smart. Most of the female characters have been shown with long hair, beautiful eyes, and ideal figure and with very thin body and sexy attire. Likewise not only the body and attire was sexy but also the body language of most of the characters was showing the sexual appeal towards the male characters. Moreover it is also observed that those animated cartoons in which the female characters were portrayed as the main and strong character, even in those the female were shown under the control and dominancy of some male character.

As for the qualitative analysis through the purposive sampling 10 most popular animated cartoons were selected to gain insight on the ideological representation of male and female characters on children's genre. All the selected animated cartoons are analyzed on the basis of gender role and appearance indicators.

\subsection{Most Popular Animated Cartoons}

\subsubsection{Ben 10}

Ben 10 is an American animated cartoon series which is produced from the Cartoon Network studios and is considered as the most popular animated cartoon series all over the world. It is a male oriented cartoon which is about ten years old boy named 'Ben Tennyson,' who has an ability to get himself to change in 10 different aliens. He always saves the universe from dangerous aliens. 'Kevin' is another male character in the cartoon that is also shown as a powerful man. While there is one prominent female character called 'Gwen Tennyson', who is also shown powerful, attractive as well as more intelligent than Ben, but Ben is always shown dominant on her.

\subsubsection{Scooby Dooby Doo}

It is also an American cartoon series which has been broadcasting since 1969 and is considered as one of popular cartoon series across the world. It's a mystery series which consists of 05 main characters Scooby Doo, a dog, 'Fred' and 'Shaggy'; two male characters while 'Dephne' and 'Velma,' two female characters. Rather Daphne is shown attractive but on the other hand the second female character of Velma is portrayed as a highly intelligent girl as compared to the male characters. This animated cartoon is male-oriented because Scooby Doo is shown as the male dog but gender portrayal is quite balanced in most of the series.

\subsubsection{Tom and Jerry}

It is a series of comedy animated cartoons which is about the rivalry relationship between a cat 'Tom' and a mouse 'Jerry'. It is also a male-oriented as well as male-dominated animated cartoon, in which the female character (the girlfriend of Tom) is shown in a very feminine role with long eye lashes and smart physique and always revealed as an attractive item for desires of Tom being a male character. 


\subsubsection{Pokémon}

It is a Japanese anime animated cartoon which is based on a video game or card game. It is also a male-oriented animated cartoon in which 'Brock and Ash' the main male characters who are ambitious and active while 'Iris and Dawn' are female characters which are shown in assisting position to Brock. Dawn is a confident who is an active trainer but on the other hand she is represented as an emotional young girl who sometime gets depressed on failure and Iris is a wild bold and adventurous girl who always loves to hang on the branches of trees in the jungle.

\subsubsection{Bakugan}

It is also a Japanese anime animated cartoon series, which is derived from a video game. It is about a young boy 'Dan' who has power and intelligence but at the same time he gets frustrated so easily. 'Runo' is the female character who is portrayed in short and sexy attire and she always loves to play with the boys. Moreover she also tries to attract the main male character Dan with her feminine attractive looks.

\subsubsection{Thunder Cats}

It is an American/Japanese fiction based animated cartoon, which is male oriented and characterized by cat like humanoid alien group. All of the male characters are shown as powerful and full of skills. Lion-o-lion is the main character who is very strong and active. Only two female characters 'Cheetara and Villy kit' are shown in this animated cartoon series and both are shown strong and active but on the other hand emotional and sexually attractive as well.

\subsubsection{Power Puff Girls}

It is an American animated cartoon series which is female-oriented and based completely on the adventures of three scientifically created young girls 'Blossom, Bubbles, Buttercup', who always fight to save the world from the villain character, which is a male monster monkey. With adventurous skills, the girls are shown in a very polite and attractive manner. One the other hand all these three girls always rely on the suggestions of male character, the young scientist for every step they have to take because that male scientist is shown more intelligent in the animated cartoon.

\subsubsection{Generator Rex}

It is also an American science fiction animated cartoon series, which is about a 15 years old boy 'Rex' that has a nature gifted ability to produce bio-organic machines from his body. It is a complete male-oriented animated cartoon which proves the men the most powerful human being on earth. 'Rebecca Holiday' is the female character who is an intelligent scientist who has to monitor the security of Rex. She is very committed towards her job.

\subsubsection{Dragon Ball Z}

It is a Japanese animated cartoon series which is based on the powerful and fighting role of male characters. It is all about action and fighting of world strongest male characters to save the world from aliens. The main character is a young muscular boy 'Goku' who claims to be the defender of universe and always fight with enemies and aliens to save the people of world. There is no female in main character but few female are shown as the side characters sometime.

\subsubsection{Batman}

It is a series of a fiction character, who is a super hero. It's a typical male-oriented animated cartoon, which is always aimed at saving the world from the evils and enemies and in the reward of his achievements he is always rewarded at the end with a female whom he saves from danger. Female characters are always shown very attractive sexually with very sexy figure and short attires.

\subsection{Common Traits of Male and Female Characters}

There are some traits of male and female characters which are revealed through the study, which are very common in most of the animated cartoons. Therefore male and female characters are portrayed in the animated cartoons more often on the basis of their physical appearance. Due to the reason of male-dominancy men are considered more powerful and strong, not only physically but also mentally. While women are always taken as a passive member of the society whose presence is meant just for the beauty of the world as well as for the personal satisfaction of men as a sexual object. Therefore from this article it is revealed that there are certain traits of male and female, which actually define their role in society. The findings from the qualitative aspect revealed data of male and female representation on the selected animated cartoon analyzed. In general male 
characters are being associated with positive stereotype, meanwhile female characters were shown in a negative stereotype.

\subsubsection{Male}

a. Strong: Having muscular and strong bodies, with a fighting capability. Always likes to face danger and looks ready for fight. Physically as well as mentally strong to conquer any kind of competition and rival. Masculine, tall and broad with muscular body and appeal for female characters. As in Generator Rex the young boy named 'Rex,' 'Lion-o-lion' in Thunder cats and 'Ben' in the form of 10 aliens is always shown to be very strong and powerful physically and this kind of portrayal confirms that being a strong person is an identified male trait.

b. Brave: Not afraid of anyone or anything, always rescue others. Most of the time shows his braveness for rescuing the women and weak persons. As 'Dan' in Bakugan is shown as a brave boy who claims to be the defender of the universe like the 'Goku' in Dragon Ball Z, who always fight with the dangerous aliens without any fear and save the world. While the character of Batman is also shown very brave and he never get scared from dangers while he always saves the scary women and old people from the hazardous situations.

c. Intelligent: Able to think rationally with intelligence and knowledge. Always gives some ideas and mindful thoughts and seems to be a real genius. Although this trait is shown in some female characters as well but in most of the animated cartoons, the male are proved to be very smart and intelligent as in "Power puff girls" the scientist who has created the power puff girls is proved to be very intelligent and he always play the role of a good guide for them. On the other hand 'Cheetara' in Thunder cats and 'Rebecca' in Generator Rex are female characters, but are shown as very intelligent one. Similarly 'Velma' in Scooby Dooby Doo is more intelligent than 'Sheggy' and 'Fred' as well as 'Gwen' in Ben 10, sometime takes more intelligent decisions than the super boy Ben 10.

d. Dominant: Always show control and supremacy over others. Most of the time shows leadership and dominancy over female and over all the other characters as well. As in the analysis of Thunder Cats and Dragon Ball $\mathrm{Z}$ the male characters are portrayed as dominant rather 'cheetara' was more active and intelligent than 'Lion-o-lion' in Thunder Cats but still she was under the dominance of male characters in that animated cartoon.

\subsubsection{Female}

a. Physically weak: Abused and victimized physically by others. Always need some male member to rescue her from danger and enemies. Unable to face the problems and difficulties alone and always get captured in some kind of victim. Not only weak but also looks passive sometimes. As in Batman female characters are proved to be physically weak most of the time. Similarly 'Dephne' in Scooby Dooby Doo is shown physically weak and sexually attractive.

b. Emotional and caring: Affectionate and caring towards others. Sometimes cries as well. Always shows love and passion as well as patience in most of the matters and towards most of the people. As 'Dawn' in Pokémon is shown active and confident but rater emotional because she always get depressed from failure and defeat of her Pokémon. 'Gwen' in Ben 10 is always shown as caring and loving towards his brother-like cousin 'Ben'. Similarly 'Villy kit' in Thunder Cats is a young and caring one towards her careless brother 'Villy kat'.

c. Sexually dressed and attractive: Beautiful and sexual attire with an attractive look and perfect physique. Always shown as a sex symbol for the viewers. With long hair and magical eyes and ideal figure, a female character is usually portrayed in most of the animated films and cartoons shown for young children. The main reason of such a representation of female characters is to prove that a woman is a sex object for the men to attract their sexual desires and attention.

As in Tom and Jerry the girl friend of Tom is always shown very sexy and attractive with smart physique and catchy eyes. At the same time female characters in Pokémon as well as in Bakugan are also shown in short attires with attractive and appealing body language and sexual attraction towards male characters. Likewise all the female characters which are shown in the series of Batman, they always have big figure and short sexy attire. One the other hand the interesting point is this that the humanoid alien cats which are playing the role of female characters in the Thunder Cats are also portrayed sexually attractive with big breast and beautiful big eyes.

d. Dependent: Dependent on others, especially on men for support and help. Always create some trouble or get indulged in some problem and then seem to be dependent on other to get rid of that trouble. Physically as well as mentally shown as dependent on the ideas and intelligence of male characters on resolving some issues or problems. As in power puff girls the three little girls are shown adventurous and intelligent but still they depend on the male scientist for most of their decisions. Similarly in Pokémon 'Dawn' is portrayed as an active and intelligent trainer but at the same time she sometimes depends on Ash for her success. Likewise, the female 
characters in Thunder Cats, 'Cheetara and Villy kit' are very active and skillful but still they could not be able to fight with enemies independently therefore finally they have to depend on 'Lion-o-lion or Tygra', the main male characters for their success.

\section{Conclusion}

Content analysis of the recent most popular animated cartoons shown on the world renowned channel for children, Cartoon Network, reveals that male-oriented animated cartoons outnumbered the female-oriented animated cartoons. Furthermore male characters are more in number than female characters which are shown on the selected channel during the certain time period. Moreover it is also proved through the findings of the study that male characters are physically more powerful and strong as well dominating while the female characters have been shown intelligent but less powerful in most of the animated cartoons.

The main difference between male and female characters was the sexually revealing attire and look of female characters as compared to the male characters in most of the animated cartoons selected and analyzed. The results show that male characters are socialized to be more strong, active and aggressive while girls are socialized to be more beautiful and sexually attractive as well as weak and passive at all. Another interesting factor which was revealed through this study was that female were represented as main character or as in the character of hero in a very few animated cartoons. While at the same time in those animated cartoons in which the female characters have been portrayed as hero, even in those cartoons they have been shown under the domination of male characters most of the time which conforms to the existing social order under the patriarchal and commercialization values.

In short the findings and results of the study proved the stereotypical representation of female characters in the animated cartoons shown on the most popular television channel of children in the world. Likewise there is an unbalanced representation of female to male characters in the animated cartoons of children. It is rather possible that such a kind of representation could convey the misleading messages to majority of children in the society. Therefore under-representation or stereotypical representation of female characters should be avoided. Stereotypes represent model to the flexible minds of children and effect their expectations of what men and women should have be like and should have to behave like in the society. Therefore this article argues that in the presence of other important agents, television is also one of the major agents in molding and shaping the gender behaviors of young children. At the end it is recommended that there should be a balanced representation of male and female characters in the animated films or cartoons so that good social and gender sensitive relationships could be established between the male and female genders to socialize them effectively and positively in the society.

\section{References}

Aries, E. (1996). Men and Women in Interaction: Reconsidering the Differences. New York: Oxford University Press.

Cosaro, W. A., \& Laura, F. (2006). Development and Socialization in Childhood. Handbook of social psychology. Kluwer Academy/ Plenum publisher, New York. http://dx.doi.org/10.1007/0-387-36921-X_6

Dietz, T. L. (1998). An Examination of violence and Gender Role portrayals in video games: Implications for Gender Socialization and aggressive behavior. Research Journal of Sex Roles, 38(5-6). http://dx.doi.org/10.1023/A:1018709905920

Dill, K. E., \& Thill, K. P. (2007). Video Game characters and Socialization of Gender Roles. Young people's perceptions mirror sexist media depictions. Sex Roles, 57.

Downs, A., \& Harrison, S. (1985). Embarrassing age spots or just plain ugly? Physical attractiveness stereotyping as an instrument of sexism on American television commercial. Sex Roles, 13, 9-19. http://dx.doi.org/10.1007/BF00287457

England, D. E., Descartes, L., \& Collier-Meek, M. A. (2001). Gender Role Portrayal and the Disney Princess. Journal of Sex Roles, 64, 555-567. http://dx.doi.org/10.1007/s11199-011-9930-7

Grusec, J. E., \& Hasting, P. D. (2007). Handbook of Socialization: theory and research. The Guilford press, New York.

Holtzman, L. (1984). Media Messages: What Film, Television and popular music teach us about race class, Gender and sexual-orientation? M. E Sharpe Inc. New York.

Jeanne, B. F., \& Debra, D. B. (1996). Children's perceptions of gender differences in social approval for playing electronic games. Journal of Sex Roles, 35(3-4). 
Klein, H., Shiffman, K. S., \& Welka, D. A. (2000). Gender-related content of animated cartoons, 1930 to the present. Advances in Gender Research, 4, 291-317. http://dx.doi.org/10.1016/S1529-2126(00)80028-4

Levinson, R. M. (1975). From Olive Oyl to sweet Polly purebred: Sex role stereotypes and televised cartoons. Journal of popular culture, 9, 561-572. http://dx.doi.org/10.1111/j.0022-3840.1975.0903_561.x

Martin, C. L., Ruble, D. N., \& Szkrybalo, J. (2002). Cognitive theories of early gender development. Psychological Bulletin, 128, 903-933. http://dx.doi.org/10.1037/0033-2909.128.6.903

Signorielli, N. (1990). Children, television and gender roles: Messages and impact. Journal of Adolescent Health Care, 11, 50-58. http://dx.doi.org/10.1016/0197-0070(90)90129-P

Silverstein, B., Perdue, L., Peterson, B., \& Kelly, E. (1986). The Role of the Mass Media in Promoting a thin Standard of Bodily Attractiveness for Women. Sex Roles, 14, 519-532. http://dx.doi.org/10.1007/BF00287452

Thomson, T. L., \& Zerbinos, E. (1995). Gender Roles in Animated cartoons: Has the picture changed in 20 years. Research Journal of Sex Roles, 32(9-10).

Williams, T. M. (1981). How and what do children learn from television? Human Communication Research, 7 , 180-190. http://dx.doi.org/10.1111/j.1468-2958.1981.tb00568.x

Wiserma, B. A. (2001). The gendered world of Disney: A content analysis of gender themes in full-length animated Disney feature films. PhD Dissertation.

\section{Copyrights}

Copyright for this article is retained by the author(s), with first publication rights granted to the journal.

This is an open-access article distributed under the terms and conditions of the Creative Commons Attribution license (http://creativecommons.org/licenses/by/3.0/). 